\title{
MEMAKNAI KINERJA PENYULUH KELUARGA BERENCANA DI KABUPATEN PASURUAN
}

\author{
Yuni Arfiani 1), Darti Djuharni2) , Hariyanto ${ }^{3)}$ \\ 1,2,3)Sekolah Tinggi Ilmu Ekonomi (STIE) Malangkuçeçwara \\ Jalan Terusan Kalasan Malang, Jawa Timur - 65142 \\ E-Mail: hariyanto@stie-mce.ac.id
}

Doi: https://doi.org/10.35606/jabm.v28i1.811

\section{Akuntansi Bisnis dan Manajemen (ABM),}

Vol. 28

No. 01

Halaman 55-65

Bulan April, Tahun 2021

ISSN 0854-4190

E-ISSN 2685-3965
Informasi Artikel

Tanggal Masuk:

15 Desember 2020

Tanggal Revisi:

31 Maret 2021

Tanggal Diterima:

08 April 2021

\section{Abstract}

The qualitative approach used in this study was carried out in accordance with the research objectives, namely interpreting the performance of family planning instructors $(K B)$ in Pasuruan district. Data were collected through in-depth interviews, observation and documentation. The stages of analysis carried out in this study were making interview transcripts; unique statements; categories of based on themes, and reduce irrelevant data. The results showed that the performance of family planning instructors was evident from the existence of hard work and smart work, good communication and coordination, and job satisfaction.

Keywords: interpretive; Family Planning Instructors; performance.

\begin{abstract}
Abstrak
Pendekatan kualitatif yang dilakukan dalam penelitian ini dilakukan sesuai dengan tujuan penelitian yaitu Memaknai Kinerja Penyuluh Keluarga Berencana (KB) di Kabupaten Pasuruan. Data dikumpulkan melalui wawancara mendalam, observasi, dan dokumentasi. Tahapan analisis yang dilakukan dalam penelitian ini adalah membuat transkrip wawancara; menginventarisasi pernyataan-pernyataan yang unik ; mengelompokkan berdasarkan tema-tema tertentu, serta mereduksi data yang tidak relevan. Hasil penelitian menunjukkan bahwa Kinerja Penyuluh KB tampak dari adanya Kerja keras dan Kerja Pintar, komunikasi dan kordinasi yang baik, dan Kepuasan kerja yang dirasakan.
\end{abstract}

Kata kunci: Interpretif; Penyuluh Keluarga Berencana; Kinerja 


\section{PENDAHULUAN}

Reformasi birokrasi tidak berjalan sesuai harapan (Ahmad, Budiningsih, Sukamto, \& Suyanto, 2017). Hal ini disebabkan adanya perencanaan pegawai yang belum sesuai dengan klasifikasi jabatan dan analisis beban kerja sehingga hasil perencanaan pegawai belum mencerminkan kebutuhan yang nyata dari suatu organisasi baik dari segi jumlah, komposisi maupun kualifikasinya. Perencanaan pegawai atau sumber daya manusia(SDM) yang tidak baik juga mengakibatkan banyak terjadi permasalahan penempatan yang dilakukan organisasi seperti menempatkan pegawai yang tidak sesuai dengan latar belakang pendidikan yang dimiliki oleh pegawai serta masih menumpuknya beberapa pegawai di bidang-bidang tertentu (Saputra, Hendriani, \& Machasin, 2017). Perencanaan SDM merupakan alat ampuh agar sumber daya manusia dapat bertahan dan loyal terhadap organisasi (Winarti, 2018). Dalam proses perencanaan pegawai, fokus utama adalah SDM itu sendiri. SDM memberikan peran dalam keberhasilan perusahaan untuk mencapai tujuannya (Erwansyah, Sulastini, \& Hereyanto, 2018). Bagaimana pun majunya teknologi saat ini, namun faktor manusia tetap memegang peranan penting bagi keberhasilan organisasi. SDM mempunyai peran utama dalam setiap kegiatan organisasi, karena SDM menjadi perencana, pelaku, dan penentu terwujudnya tujuan sistem organisasi (Arifudin, Sudirman, \& andri, 2017). Untuk mencapai tujuan organisasi harus ditunjang dengan kinerja pegawai yang baik, yang menurut Hendratmoko (2013) dapat diperoleh melalui penilaian kinerja.

Suatu Instansi perlu melakukan penilaian kinerja pegawai untuk mengetahui keberhasilan atau ketidakberhasilan dalam melaksanakan tugas (Saefudin \& Wahyuningsih, 2014). Penilaian kinerja dapat dikatakan sebagai faktor utama dalam pengembangan suatu perusahaan, karena hal ini merupakan sebuah sarana bagi manajemen untuk menelaah sejauh mana visi misi perusahaan telah tercapai(Christina \& Sudana, 2013). Penilaian kinerja sangat penting dan harus dilakukan secara berkala. Hasil penilaian kinerja sangat diperlukan untuk pengambilan keputusan tentang pegawai, baik mengenai pengembangan karir maupun yang berkaitan dengan imbalan atau upah, yang dikalangan Pegawai Negeri dikenal dengan Gaji atau Tunjangan Kinerja (Setiawan, 2019). Faktor-faktor yang mempengaruhi kinerja diantaranya adalah motivasi kerja, kualitas kerja dan kompensasi (Sakban, Nurmal, \& Ridwan, 2019). Kompensasi merupakan salah satu kebutuhan utama yang diperlukan karyawan untuk memenuhi kebutuhan hidupnya (Putrianti, Hamid, \& Mukzam, 2014). Pemberian kompensasi harus dilakukan secara adil dan merata agar tercipta lingkungan kerja. Menurut Elizar and Tanjung (2018) lingkungan kerja yang baik dan menyenangkan akan dapat menimbulkan semangat dan gairah kerja, dan sebaliknya lingkungan kerja yang tidak menyenangkan akan dapat mengurangi semangat dan gairah kerja. Gairah dan semangat untuk bekerja secara optimal dapat ditumbuhkan oleh faktor motivasi kerja. Penyuluh KB yang memiliki motivasi kerja yang tinggi akan mempunyai banyak energi untuk melaksanakan pekerjaannya (Pujiyanto, Puspita, \& Harsanto, 2017).

Beberapa penelitian dengan obyek Penyuluh Keluarga Berencana seperti yang dibahas oleh Irmawati, Hasanuddin, and Adda (2018) menyimpulkan bahwa motivasi dan kompetensi berpengaruh signifikan terhadap kinerja Petugas Lapangan Keluarga 
Berencana dalam melakukan pengelolaan program KB di Kota Palu. Penelitian lain juga dilakukan (Rusmiah, Brasit, \& Mardiana, 2019) menyimpulkan bahwa karakteristik individu, kompetensi dan lingkungan kerja secara simultan berpengaruh positif dan signifikan terhadap kinerja Penyuluh Keluarga Berencana di Kabupaten Mamuju. Penelitian tentang kinerja Penyuluh Keluarga Berencana yang dilakukan oleh Hutanto, Djumlani, Apriani, and Fajar. (2014) menyimpulkan bahwa kinerja Penyuluh KB pada Badan Keluarga Berencana dan Keluarga Sejahtera Kota Samarinda masih kurang optimal dalam menjalankan tupoksinya ${ }^{1}$ dilihat dari sisi kualitas pekerjaan, keterampilan pegawai, dan disiplin kerja.

Berdasarkan penelitian terdahulu yang lebih banyak menggunakan hipotesis dalam kajiannya, maka di sini peneliti ingin melakukan kajian terhadap kinerja Penyuluh KB pada Dinas Keluarga Berencana dan Pemberdayaan Perempuan Kabupaten Pasuruan. Penelitian ini mirip dengan kajian yang dilakukan Hutanto et al. (2014), namun dilakukan pada obyek yang berbeda. Selain itu kajian yang dilakukan oleh Hutanto et al. (2014) dilakukan dengan pendekatan positivis, sedangkan pada penelitian ini menggunakan pendekatan non positivis. Hal ini didasarkan pada tujuan penelitian yaitu Memaknai Kinerja Penyuluh KB di Kabupaten Pasuran dengan memperhatikan tupoksi tambahan dari Kementerian Pemberdayaan Perempuan dan Perlindungan Anak.

\section{METODE PENELITIAN}

Pendekatan interpretif yang digunakan dalam kajian ini, sesuai dengan tujuan penelitian yang ingin memaknai kinerja penyuluh KB di Kabupaten Pasuruan. Oleh karena itu sebagaimana yang disampaikan (Djuharni, 2018) bahwa penelitian yang tujuan untuk memaknai sesuatu, tergolong dalam penelitian interpretif yang masuk dalam ranah penelitian kualitatif. Penelitian kualitatif didasarkan pada karakteristik berikut sebagaimana yang disampaikan Creswell (2013), yaitu (1) penelitian dilakukan secara alamiah dan interaksi dengan sumber data sangat dekat; (2) peneliti merupakan instrumen kunci dalam pengumpulan data; dan (3) menggunakan berbagai metode dalam pengumpulan data. Semua karakteristik yang diuraikan ini terkait dengan penelitian yang dilakukan saat ini, karena peneliti sebagai instrumen kunci melakukan sendiri pengumpulan dan analisis data. Kedekatan peneliti dengan sumber data juga merupakan bagian dari kegiatan penelitian ini, karena peneliti bekerja di lingkungan departemen dimana sumber data penelitian ini diperoleh.

Dalam penelitian ini data dikumpulkan melalui wawancara mendalam, observasi, , dan dokumentasi. Informan penelitian sebanyak sepuluh orang terdiri atas Pejabat Struktural yang ada di lingkungan Dinas Keluarga Berencana dan Pemberdayaan Perempuan Kabupaten Pasuruan dan dari unsur Penyuluh KB. Wawancara dengan sepuluh informan ini sebagian besar dilakukan melalui obrolan melalui whatsapps karena pengumpulan data dilakukan saat diberlakukannya PSBB saat adanya pandemi covid-19. Daftar sepuluh informan tersebut ditampilkan pada tabel 1 berikut ini.

\footnotetext{
1 tupoksi $=$ tugas pokok dan fungsi
} 
Tabel 1. Daftar Informan

\begin{tabular}{|c|c|c|c|}
\hline No & Nama & Pendidikan & Jabatan \\
\hline 1. & $\begin{array}{l}\text { Drg. Loembini Pedjati } \\
\text { Lajoeng }\end{array}$ & $\begin{array}{l}\text { Dokter } \\
\text { spesialis }\end{array}$ & Kepala Dinas KB dan PP \\
\hline 2. & $\begin{array}{l}\text { Dra. Hendah Sholchah, } \\
\text { MM }\end{array}$ & S2 & Kepala Bidang Pemberdayaan Perempuan \\
\hline 3. & Anggono Kurniawan, SH & S1 & Kepala Seksi Pengendalian Penduduk \\
\hline 4. & Drs. Nursamhadi, MM & S2 & $\begin{array}{l}\text { Ketua Ikatan Penyuluh KB Kabupaten } \\
\text { Pasuruan }\end{array}$ \\
\hline 5. & Ani Widjiastuti, SH & S1 & Koordinator Penyuluh KB Kecamatan Bangil \\
\hline 6. & Meita Yuliawati, SP & S1 & Koordinator Penyuluh KB Kecamatan Kraton \\
\hline 7. & $\begin{array}{l}\text { Dwi Atika Widhiastuti, } \\
\text { SKM }\end{array}$ & S1 & Penyuluh KB Kec. Gempol \\
\hline 8. & Nurhayati & SMA & Penyuluh KB Kecamatan Beji \\
\hline 9. & Masroin & SMA & Penyuluh KB Kecamatan Gempol \\
\hline 10. & Tutut & SMA & $\begin{array}{l}\text { Kader PPKBD Desa Cangkringmalang } \\
\text { Kecamatan Beji }\end{array}$ \\
\hline
\end{tabular}

Selain wawancara, data dikumpulkan juga melalui observasi dengan cara mengamati secara langsung kinerja Penyuluh KB di lapangan serta interaksi dengan masyarakat khususnya untuk Pasangan Usia Subur. Untuk melengkapi data, peneliti juga membuat dokumentasi atas segala aktifitas yang dilakukan, dan memanfaatkan dokumen-dokumen pendukung yang dimiliki dinas KBPP sebagai bahan analisis data.

Analisis data dilakukan dengan tahapan (1) membuat transkrip wawancara dalam bahasa tulisan; (2) menginventarisasi pernyataan-pernyataan penting yang relevan dengan topik; (3) mengklasifikasikan pernyataan-pernyataan ke dalam tematema, serta menyisihkan data yang tumpang tindih atau berulang-ulang; (4) dan menyajikan hasil analisis dan pembahasan dalam bentuk laporan penelitian.

\section{HASIL DAN PEMBAHASAN}

Penyuluh KB di Kabupaten Pasuruan pada tahun 2020 berjumlah 80 orang, yang mana setiap Penyuluh KB membawahkan desa binaan yang tersebar pada 24 kecamatan di seluruh Kabupaten Pasuruan. Berikut tabel jumlah Penyuluh KB Kabupaten Pasuruan beserta desa binaannya.

Tabel.2 Data Pkb Dan Desa Binaan Di Kabupaten Pasuruan Tahun 2020

\begin{tabular}{clcc} 
No & Nama Kecamatan & Jumlah PKB (orang) & Jumlah Desa Binaan \\
\hline 1 & Purwodadi & 4 & 13 \\
2 & Tutur & 3 & 12 \\
3 & Puspo & 1 & 7 \\
4 & Lumbang & 3 & 12 \\
5 & Pasrepan & 2 & 17 \\
6 & Kejayan & 4 & 25 \\
7 & Wonorejo & 3 & 15 \\
8 & Purwosari & 3 & 15
\end{tabular}




\begin{tabular}{clcc}
9 & Sukorejo & 3 & 19 \\
10 & Prigen & 3 & 14 \\
11 & Pandaan & 2 & 18 \\
12 & Gempol & 5 & 15 \\
13 & Beji & 4 & 14 \\
14 & Bangil & 4 & 15 \\
15 & Rembang & 5 & 17 \\
16 & Kraton & 6 & 25 \\
17 & Pohjentrek & 3 & 9 \\
18 & Gondang wetan & 5 & 20 \\
19 & Winongan & 4 & 18 \\
20 & Grati & 3 & 15 \\
21 & Nguling & 2 & 15 \\
22 & Lekok & 3 & 11 \\
23 & Rejoso & 3 & 16 \\
24 & Tosari & 2 & 8 \\
& Jumlah & 80 & 365 \\
\hline mber: Dinas Keluarga Berencana dan Pemberdayaan Perempuan Kabupaten Pasuruan
\end{tabular}

Data penyuluh KB sebagaimana ditunjukkan dalam tabel 2, tampak bahwa ratarata setiap penyuluh KB menangani empat desa binaan. Hal ini menggambarkan beban tugas yang diemban oleh setiap penyuluh $\mathrm{KB}$ dengan beragam pekerjaan yang harus dilakukannya. Penyuluh KB harus menjalankan tugas yang terkait dengan bidang Keluarga berencana dan program yang terkait dengan pemberdayaan perempuan dan perlindungan anak. Sesuai tahapan analisis yang telah diuraikan sebelumnya, maka hasil penelitian yang telah ditranskipkan kemudian dikelompokkan berdasarkan tema, diinterpretasikan, dan disajikan. Tema-tema yang ditemukan berdasarkan hasil analisis terkait dengan kinerja penyuluh KB diuraikan berikut ini.

\section{Kerja Keras dan Kerja Pintar}

Jenis pekerjaan penyuluh KB di Kabupaten Pasuruan dinilai berdasarkan tupoksi yang telah ditentukan, tetapi seringkali ada pekerjaan yang harus dikerjakan di luar tugas pokok, dan itu menuntut kemampuan dan kemauan setiap penyuluh KB untuk menyelesaikan semua tugas yang dibebankan kepadanya. Hal ini terungkap dari wawacara dengan informan 6 yang mengatakan:

...di Dinas KBPP itu bergabung dengan Pemberdayaan Perempuan.. nah itu kita megang dua Kementrian otomatis.. PP2 dan BKKBN.. dua Kementrian tupoksinya ini oleh Dinas ditumpukan ke Penyuluh KB, nah itu yang mungkin agak membuat kami kesulitan..seperti kita ngge.. kalau misalkan BKKBN gimanapun kita juga sudah hapal rumusnya tapi kalau Pemberdayaan Perempuan itu programnya terus-terusan gitu lho, dan mungkin ada beberapa program yang punya tujuan dan sasaran yang sama dari PP tapi caranya kadang berbeda juga apa namanya, terus untuk PP contoh aja la.. kalau ada kekerasan di wilayah kita..

\footnotetext{
$2 \mathrm{PP}=$ pemberdayaan perempuan
} 
Menurut informan ini, tupoksi penyuluh KB tidak berubah tetapi karena sekarang beban tugasnya ditambah karena ada penggabungan dengan Pemberdayaan Perempuan, maka penyuluh $\mathrm{KB}$ tidak hanya menyelesaikan urusan terkait dengan keluarga berencana saja, tetapi juga segala persoalan yang timbul di masyarakat terkait dengan perempuan.

...tupoksinya tetep ngge.. karena tupoksi kita tidak berubah, sesuai Permenpan itu.. tapi eh.. kalau yang di Kabupaten Pasuruan, Kabupaten Pasuruan itu sepertinya beban kita ditambahi berat ya.. kita khan komunikasi langsung dengan BKKBN ataupun perwakilan BKKBN prop. Jatim.. kadang mereka meminta data ini harus masuk, kerjaan ini harus selesei saat ini juga.

Hal ini diperkuat oleh informan no 7 yang mgengatakan:

...."boleh sih tapi ya kita dibantu juga untuk treatment nya itu seperti apa karena bukan tugas pokoknya juga, memang kita memang membina masyarakat namun seperti itu juga menjadi beban juga..."

Berdasarkan hasil wawancara ini dapat disimpulkan bahwa seorang penyuluh KB harus mampu menyelesaikn semua persoalan terkait dengan keluarga berencana, sekaligus juga harus mau dan mampu menyelesaikan persoalan terkait dengan pemberdayaan perempuan. Hal ini dikarenakan adanya penggabungan dua kementerian yaitu Pemberdayaan Perempuan dan BKKBN. Sebelumnya penyuluh KB hanya melaksanakan tugas terkait dengan Keluarga Berencana, namun saat ini ditambah dengan tugas terkait pemberdayaan perempuan. Tugas yang terkait dengan keluarga berencana bagi mereka tidak ada kendala karena mereka sudah hafal dan terbiasa, tetapi tugas yang terkait dengan pemberdayaan perempuan merupakan beban tersendiri karena keterbatasan kemampuan yang dimiliki setiap penyuluh KB. Hal ini dikarenakan kegiatan jenis ke dua ini tidak pernah ada ujungnya belum lagi jika ada kasus kekerasan atau kasus lainnya yang berhubungan dengan perempuan yang tidak sepenuhnya dapat diselesaikan oleh penyuluh KB karena keterbatasan kemampuan mereka.

Beratnya beban yang harus diemban para penyuluh KB juga disebabkan tenaga kerja yang tersedia sangat terbatas sedangkan tugas yang diemban cukup banyak dan rumit. Hal ini sebagaimana diungkap oleh informan 6.

...Kalau kita yang bergerak otomatis kader KB yang dipakai, lha kader KB khan di desa, sesuai dusun.. sedangkan kader posyandu satu posyandu disetiap dusunnya itu ada 5 kader, kalau misalnya di desa ada 5 dusun ya dia 25 kader.. sementara kalau KB, kita hanya 5 kader. 5 kader itu sudah dibebani oleh program pembangunan keluarga terus program yang lainnya dari BKKBN.. dia ditumpuki dengan program riskan yang seperti ini, ya jelas.. kekerasan khan riskan, kadang sudah diurus-uruskan sampai ke.. sampai ke Polres...

Ada lagi tugas yang harus dikerjakan oleh penyuluh $\mathrm{KB}$ yang tidak didanai pemerintah tetapi inisiatif petugas atau penduduk setempat. Pekerjaan itu tetap dilakukan dengan niat ibadah, seperti yang disampaikan oleh informan 8 .

Saya sebenarnya sudah mengajukan dana lewat Musrenbangdes untuk kegiatan desa tapi ga pernah terealisasi, kita sudah memberikan penjelasan, sudah ada payungnya. tapi ga terealisasi... Tapi itu menyeluruh kok. he..emmm.. makanya itu seharusnya itu bagaimana supaya bisa terbentuk, sampai bu Bidan itu merelakan tanahnya untuk 
dibuat taman bermain, tapi khan membuat taman juga butuh biaya, karena kita membersihkan dan merawat, kita ga bisa sama Bidan saja, harusnya ya sama Desa juga.. untuk tanama

.....Untuk PKK ga ada dukungan dana.. yo wes.. niat ibadah itu tadi.. kegiatan PKK khan banyak sekali, ngalah-ngalahi dinas khan??"

Berdasarkan uraian ini tampak bahwa penyuluh KB saat ini harus melaksanakan tugas yang lebih banyak dengan tenaga kerja yang ada, dibandingkan saat menjadi pegawai daerah yang hanya khusus melayani penyuluhan tentang keluarga berencana. Banyak aktifitas yang harus dilakukan oleh penyuluh KB yang tidak masuk dalam tupoksinya dan tidak masuk dalam anggaran pemerintah, sebagaimana terungkap dalam wawancara dengan informan yang telah diuraikan sebelumnya. Itu artinya penyuluh KB harus mapu untuk melakukan kerja keras dan kerja pintar dengan memanfaatkan fasilitas dan dana yang tersedia.

\section{Kordinasi dan Komunikasi yang Efektif}

Banyaknya jumlah pekerjaan yang harus dilakukan dan terbatasnya kemampuan penyuluh KB, serta luasnya cakupan wilayah yang harus ditangani merupakan motivasi dari penyuluh KB untuk selalu menjalin hubungan baik dengan masyarakat, sesama pekerja, juga dengan pimpinan. Hal ini dibutuhkan karena penyuluh KB perlu melaksanakan program yang menyangkut keluarga berencana, ditambah dengan kegiatan pemberdayaan perempuan dan perlindungan anak. Komunikasi yang baik sangat diperlukan oleh penyuluh $\mathrm{KB}$, karena salah satu tugas mereka adalah memberi penyuluhan kepada masyarakat, sebagaimana yang dikatakan oleh informan 5 berikut ini.

......Penyuluhannya ya ke rumah kader-kader, ke kader-kader.. ngasihkan pil, sama tanyatanya kira-kira selama ini yang biasanya minta pil Kb yang ikut KB ada ga yang ga ikut KB hamil, saya suruh antisipasi agar orang-orang jangan sampai ga ikut KB. Ga pake pil atau lainnya, resikonya khan tinggi... musim covid ini mereka hamil........

Pernyataan informan ini menunjukkan bahwa penyuluh KB tidak bekerja untuk kepentingannya sendiri melainkan dia harus membaur dengan masyarakat yang membutuhkan terutama memberi penyuluhan. Ini artinya setiap penyuluh $\mathrm{KB}$ harus pandai berkomunikasi agar apa yang disampaikannya dapat dipahami dan dilaksanakan oleh pihak lain. Di samping itu koordinasi yang baik antara penyuluh KB dengan lingkungan dan pemerintah sangat diperlukan dalam kegiatan mereka. Hal ini sebagaimana disampaikan oleh informan 3 berikut ini.

Eh.. gini mbak..temen-temen di lapangan itu harus pandai-pandai dalam menempatkan diri, karena bagaimanapun juga mereka kegiatannya nempel di kecamatan.. oleh karena itu pemanfaatannya kita ga 100 persen mutlak karena mereka bisa harus ngemong yang di kec.. kami juga memberikan pesan kpd mereka tementemen lapangan agar bisa menerjemahkan apa yg dikatakan pimpinan wilayahnya, dalam hal ini pak camat...

Dari uraian sebelumnya tampak bahwa setiap penyuluh KB harus mampu dan mau berkomunikasi dengan baik dan berkoordinasi dengan pihak-pihak terkait agar pekerjaan yang dilakukan dapat berjalan lancar dan memberikan hasil yang 
memuaskan untuk semua pihak. Kondisi ini ditunjukkan dari hasil wawancara dengan informan 6

...target itu yang harus kita penuhi, antara lain seperti peserta KB aktif, peserta KB baru kemudian target poktan itu segala macam, itu harus kita penuhi termasuk juga angka unmeet need nya kita tidak boleh melebihi dari provinsi, kalau lebih dari provinsi.. provinsi kalau untuk 2019 menetapkan.. eh 2020 ini provinsi menetapkan PPM untuk unmeet need itu sekitar 4 koma berapa persen gitu...

Begitu juga yang dikatakan oleh informan 8, bahwa penyuluh KB telah memenuhi target yang ditetapkan dan laporan yang dikirimkan tidak pernah terlambat.

....Ga.. ga pernah telat, alhamdulillah la itu tadi kita punya asisten, kita konsep, kita dampingi, anak sekarang khan pinter-pinter.. pokoknya sesuai dengan aturan yang ada walaupun kita tidak bisa tetapi kita tetap melaksanakan tugas dengan penuh tanggung jawab tetap membuat DUPAK. pokoknya DUPAK bisa berjalan, e visum kita kerjakan setiap gerak, kita isi.. pokoke sesuai aturan aja kita ikuti...

Di sisi lain informan 2 mengatakan bahwa sebagai perpanjangan tangan pemerintah, penyuluh KB harus mampu dan mau berkoordinasi dengan pihak lain, seperti yang dikatakannya berikut ini,

.... kita memang leading sector tapi untuk yang melaksanakan program adalah semua Organisasi Perangkat Daerah, kalangan masyarakat, peran masyarakat, dunia usaha, media massa, lembaga masyarakat itu turut campur, istilahnya menangani prinsipnya untuk mewujudkan hal seperti itu, nah temen-temen Penyuluh KB adalah tangan panjang yang Dinas KBPP bisa koordinasi, mengkoordinasikan, melinkkan, jejaring. Tapi kalau melaksanakan bukan, itu bukan tugas murni dari KBPP, contoh ni Kecamatan Layak Anak disitu ada berapa anak yang sudah sekolah, berapa yang putus sekolah.. berarti khan Dinas Pendidikan khan mba ya.....

Berdasarkan uraian sebelumnya dapat disimpulkan bahwa kordinasi dan komunikasi merupakan hal yang penting dan harus dilakukan oleh setiap penyuluh KB.

\section{Kepuasan Kerja}

Hal lain yang dapat dimaknai dari kinerja penyuluh KB adalah kepuasan kerja. Bagi sebagian orang menjadi penyuluh KB merupakan hal yang menyenangkan, karena pekerjaannya bervariasi dan tidak monoton, hal ini sebagaimana dikatakan oleh informan 5 dan 6 berikut ini,

.....seneng berhadapan dengan banyak masyarakat, dengan berbagai macam karakter.. dan apa ada kebahagiaan tersendiri kita bermacam-macam masyarakat dengan karakter yang berbeda-beda.. itu tidak membuat kita jenuh (informan 5).

ya.. kalau sukanya tiap hari kita ritme kerjanya ga itu-itu aja, kalau di kantor khan kita berhadapan dengan kertas, tugas kita ini, tugas kita itu...(informan 6).

begitu juga yang disampaikan oleh informan 8 yang mengatakan:

...Suka nya jadi penyuluh KB karena banyak saudara.. iya, kita sama kader-kader yang begitu banyaknya semua menjadi saudara... saling membantu, saling membutuhkan, mengetahui kehidupan masyarakat yang majemuk, karakternya bermacam-macam di desa ya..... 
Berdasarkan uraian sebelumnya dapat dikatakan bahwa menjadi penyuluh KB merupakan hal yang menyenangkan karena bisa memiliki banyak kenalan dan saudara, pekerjaan yang dilakukan beraneka ragam sehingga tidak membuat jenuh, juga lokasi tempat dilakukannya penyuluhan berbeda-beda. Kondisi ini tentunya dapat pula menjadi motivasi penyuluh KB dalam menyelesaikan tugas-tugasnya. Penjelasan yang telah diuraikan sebelumnya dapat dirangkum dalam satu kalimat berikut ini.

Kinerja penyuluh KB didasarkan pada kemampuan dan kemauan dari diri setiap individu untuk melakukan kerja keras dan kerja pintar, tanpa mengabaikan perlunya kordinasi dan komunikasi yang baik, sehingga pekerjaan yang dijalankan dan dihasilkan memberi rasa puas dan menyenangkan bagi pelaksananya.

\section{KESIMPULAN DAN SARAN}

Penyuluh KB di kabupaten Pasuruan telah melaksanakan tugas sesuai dengan TUPOKSI yang ditetapkan, namun kondisi saat ini tugas mereka semakin berat dan kompleks karena sebelumnya mereka hanya menangani persoalan yang terkait dengan keluarga berencana, saat ini ditambah dengan pemberdayaan perempuan dan penanggulangan anak. Untuk tugas yang terkait dengan keluarga berencana bagi mereka bukanlah hal yang sulit, karena sudah terbiasa dengan kegiatan itu sejak awal, tetapi kegiatan tambahan yang diberikan membuat mereka agak kewalahan karena persoalan yang dihadapi sangat komplek. Oleh karena itu setiap penyuluh KB dituntut untuk dapat melakukan pekerjaannya dengan baik melalui kerja keras dan kerja pintar, menjalin koordinasi dengan pihak terkait, dan kemampuan berkomunikasi yang baik. Dengan demikian mereka merasa puas dengan kerja yang dilakukannya.

Penelitian ini dilakukan di masa pandemi Covid-19, sehingga kegiatan wawancara banyak dilakukan melalui telepon dan media sosial lainnya yang kadangkadang terganggu karena ada kendala sinyal. Kondisi ini mengakibatkan peneliti tidak dapat menggambarkan secara langsung reaksi, ekspresi, dan bahasa tubuh informan saat menjawab pertanyaan peneliti. Oleh karena itu penelitian ini dapat dilanjutkan dengan menggunakan metode lain misalnya dengan menggunakan etnografi agar dapat diungkap kekebiasaan melalui adat istiadat dan budaya setempat agar dapat digali lebih jauh lagi makna kinerja bagi penyuluh KB.

\section{DAFTAR PUSTAKA}

Ahmad, M., Budiningsih, I., Sukamto, H., \& Suyanto, B. (2017). AHMAD, Masduki, et al. Faktor-Faktor Yang Mempengaruhi Keberhasilan Reformasi Birokrasi Di Lembaga Pemerintah. International Journal of Economic Research (IJER), 2017, 1-16. International Journal of Economic Research (IJER), 1-16.

Arifudin, Sudirman, \& andri, M. (2017). Evaluasi Sistem Manajemen Sumber Daya Manusia Pada Penempatan Kerja Petugas Di Upt Puskesmas Lembasada. Promotif, Vol.7(No.1), 1-14.

Christina, N. P. Y., \& Sudana, I. P. (2013). Penilaian Kinerja Pada Pt. Adhi Karya Dengan Pendekatan Balanced Scorecard. E-Jurnal Akuntansi Universitas Udayana, 5(3), 516-529. 
Creswell, J. W. (2013). Qualitative Inquiry and Research Design: Choosing Among Five Approaches (Third). USA: Sage Publication, Inc. USA: Sage Publication, Inc.

Djuharni, D. (2018). Sistem Informasi Akuntansi dalam Perspektif Budaya Minangkabau. Doctoral Disertasi, Universitas Brawijaya, Malang.

Elizar, \& Tanjung, H. (2018). Pengaruh Pelatihan, Kompetensi, Lingkungan Kerja terhadap Kinerja Pegawai. Maneggio: Jurnal Ilmiah Magister Manajemen Vol 1(No.1), 46-58. doi: https:// doi.org/10.30596/maneggio.v1i1.2239

Erwansyah, M., Sulastini, \& Hereyanto. (2018). Pengaruh Kompetensi, Disiplin Kerja Dan Lingkungan Kerja Terhadap Kinerja Pegawai (Survey Pada PT. Bank Negara Indonesia (Persero) Tbk Kantor Cabang Muara Teweh Kabupaten Barito Utara). Jurnal Bisnis dan Pembangunan, Vol 7(No.1).

Hendratmoko, C. (2013). Pengaruh Implementasi Manajemen Sumber Daya Manusia Berbasis Kompetensi Terhadap Kepuasan Kerja dan Kinerja Pegawai (Studi Di Kantor Bank Jateng). Doctoral Degree Disertasi, Universitas Diponegoro, Semarang.

Hutanto, Djumlani, A., Apriani, \& Fajar. (2014). Analisis Kinerja Petugas Penyuluh Lapangan Keluarga Berencana (PLKB) pada Badan Keluarga Berencana Dan Keluarga Sejahtera Kota Samarinda. . EJournal Administrative Reform Universitas Mulawarman, 2(3), 1941-1953.

Irmawati, Hasanuddin, B., \& Adda, H. (2018). Pengaruh Kompetensi Dan Motivasi Terhadap Kinerja Petugas Lapangan Keluarga Berencana (Plkb) ) Dalam Pengelolaan Program Kb Di Kota Palu. e Jurnal Katalogis, Volume 6(Nomor 4), 178-186.

Pujiyanto, N. D., Puspita, D. R., \& Harsanto, B. T. (2017). Pengaruh Kompetensi, Motivasi, Lingkungan Kerja Dan Persepsi Gaya Kepemimpinan Terhadap Kinerja Penyuluh Keluarga Berencana. Masyarakat, Kebudayaan dan Politik Vol.30(No.3), 278-289.

Putrianti, A. D., Hamid, D., \& Mukzam, M. D. (2014). Pengaruh Kompensasi Dan Motivasi Kerja Terhadap Turnover Intention. Jurnal Administrasi Bisnis (JAB)|, 12(2).

Rusmiah, Brasit, N., \& Mardiana, R. (2019). Pengaruh Karakteristik Individu, Kompetensi, Dan Lingkungan Kerja Terhadap Kinerja Penyuluhan Keluarga Berencana Kabupaten Mamuju Provinsi Sulawesi Barat. Hasanuddin Journal of Applied Business and Entrepreneurship, 2(no.4), 98-107.

Saefudin, S., \& Wahyuningsih, S. (2014). Sistem Pendukung Keputusan Untuk Penilaian Kinerja Pegawai Menggunakan Metode Analytical Hierarchy Process (Ahp) Pada RSUD Serang. Jurnal Sistem Informasi (JSiI), 1(1), 33-37. doi: https://doi.org/10.30656/jsii.v1i0.78

Sakban, Nurmal, I., \& Ridwan, R. b. (2019). Manajemen Sumber Daya Manusia. Alignment: Journal of Administration and Educational Management, Vol.2(No.1), 93104. doi: https:// doi.org/10.31539/alignment.v2i1.721

Saputra, B. Y., Hendriani, S., \& Machasin. (2017). Pengaruh Kompetensi Dan Penempatan Terhadap Semangat Kerja Dan Kinerja Pegawai Dinas Pendapatan Daerah Kabupaten Bengkalis. Jurnal Tepak Manajemen Bisnis, IX(2), 1-20. 
Setiawan, H. (2019). Strategi Penilaian Kinerja Dalam Pendidikan (Performance Evaluation Startegy)." At-Ta'lim: Kajian Pendidikan Agama Islam. At-Ta'lim: Kajian Pendidikan Agama Islam, 1(1), 15-30.

Winarti, E. (2018). Perencanaan manajemen sumber daya manusia lembaga pendidikan. Tarbiyatuna. Jurnal Pendidikan Ilmiah, 3(1), 1-26. 